\title{
Recent Changes in Rainfall, Temperature and Number of Rainy Days over Northern Oromia Zone, Ethiopia
}

\author{
Asaminew Teshome Game, Diriba Korecha (PhD)* \\ Data Processing and Climatology case team Coordinator, National Meteorological Agency (NMA) of Ethiopia, Addis Ababa, Ethiopia
}

Email address:

asmin2met@gmail.com (A. T. Game)

\section{To cite this article:}

Asaminew Teshome Game, Diriba Korecha. Recent Changes in Rainfall, Temperature and Number of Rainy Days over Northern Oromia Zone, Ethiopia. Science Discovery. Vol. 3, No. 6, 2015, pp. 62-70. doi: 10.11648/j.sd.20150306.14

\begin{abstract}
Agriculture is one of the sectors most vulnerable to climate change impact. The main economy of the study area is mainly dependent on rain-fed agriculture, the failure or the goodness of seasonal and annual rainfall amount is extremely critical because the study areas socio economic functioning particularly, food production. Changes in annual, June-September and March-May rainfall and rainy days herein (defined as a day with rainfall greater than $0.1 \mathrm{~mm}$ ) have been analyzed based on 4 stations located in North Oromia zone (R4) of different climatic zones for the common period 1982-2014. The aim of this study was to characterize the climate of the study areas. This study was conducted in Northern Oromia region part of Ethiopia. Historical climate data (1982-2014), were collected from National Meteorological Agency. Instat+v.3.37 and Excel 2010 were used for analysis of rainfall and temperature variability and trend analysis. Time series anomaly plots for temperature showed that the mean maximum temperature over Filiklik, Werejarso, Gerbeguracha and Fitche has increased by about 0.5 to $2^{\circ} \mathrm{C}, 0.5$ to $1.55^{\circ} \mathrm{C}$ and 0.5 to $1.5^{\circ} \mathrm{C}$ and 0.5 to $1.5^{\circ} \mathrm{C}$ respectively. Whereas minimum temperature also increased by 0.5 to $2^{\circ} \mathrm{C}, 0.5$ to $1.5^{\circ} \mathrm{C}$ and 0.5 to $1.5^{\circ} \mathrm{C}$ over Filiklik, Gerbeguracha and Fitche respectively but in the past few recent years minimum temperature showed slight decrement at Werejarso. While the rainfall amount and number of rainy days showed slight variability during the period of 1982-2014. The number of rainy days shows that decrement by $5.8 \%$ and $4.2 \%$ over Filiklik and Werejarso. On the hand numbers of rainy days were stationary over Gerbeguracha and Fitche for the last thirty two years. Strengthen of further research on the impact of climate change and variability on different socio-economic activities of the societies is very crucial.
\end{abstract}

Keywords: Temperature, Rainfall and Number of Rainy Days Variability, Instat+v.3.37

\section{Introduction}

The climate of Africa is warmer than it was 100 years ago and model-based predictions of future GHG induced climate change for the continent clearly suggest that this warming will continue and in most scenarios accelerate (Hulme, 2001). Observational records show that during the 20th century the continent of Africa has been warming at a rate of about $0.05^{\circ} \mathrm{C}$ per decade with slightly larger warming in the June-November seasons than in December-May (Hulme, 2001). By 2000, the five warmest years in Africa had all occurred since 1988, with 1988 and 1995 being the two warmest years. This rate of warming is not dissimilar to that experienced globally, and the periods of most rapid warming the 1910 s to 1930 s and the post-1970s occur simultaneously in Africa and the rest of the world (IPCC, 2001).

Ethiopia is already experiencing change in its climate. Between 1951 and 2006 annual minimum temperature in
Ethiopia has been increased by about $0.37^{\circ} \mathrm{C}$ every decade. The UNDP Climate Change profile for Ethiopia also shows that the mean annual temperature has increased by $1.3^{\circ} \mathrm{C}$ between 1960 and 2006, at an average rate of $0.28^{\circ} \mathrm{C}$ per decade (McSweeney., 2010). The temperature increase has been most rapid from July to September $\left(0.32^{\circ} \mathrm{C}\right.$ per decade). Reportedly, the average number of hot days per year has increased by 73 (an additional $20 \%$ of days) and the number of hot nights has increased by 137 (an additional 37.5\% of nights) between 1960 and 2006. The rate of increase was highest in June, July and August. Over the same period, the average number of cold days and nights has decreased by 21 (5.8\% of days) and 41 (11.2\% of nights), respectively. These reductions have mainly occurred in the months of September to November (McSweeney., 2010).

Furthermore, a study on climate change projections specific to Ethiopia, undertaken by the University of Oxford, depicts that mean annual temperature in the country would increase by 1.1 to $3.1^{\circ} \mathrm{C}$ by the $2060 \mathrm{~s}$, and 1.5 to $5.1^{\circ} \mathrm{C}$ by the $2090 \mathrm{~s}$ 
and could reduce GDP by $3-10 \%$ by 2025 (McSweeney., 2010). The study also found that projections from different climate models were broadly consistent in indicating increases in average rainfall in Ethiopia, primarily through increases in rainfall during the shorter of southern Ethiopia's two rainy seasons (in October, November and December), with more mixed projections for the rest of the country and that more rain would fall in 'heavy' events (Alex, 2012). Of all the economic sectors, agriculture is the most vulnerable to climate variability and increased frequency of extreme events (Anju, 2007). This is because crop productivity in many environments (particularly in the tropical regions which is characterized by low levels of technological interventions) is highly dependent on weather and climate (Challinor A. J., 2004). Similarly, Ethiopian agriculture is mostly characterized by extreme dependence on rained system (Woldeamlak, 2009).

The amount and temporal distribution of rainfall is generally the single most important determinant of inter-annual fluctuations in national crop production levels (Woldeamlak, 2009). Whereas, inter-annual and seasonal rainfall variability is high and droughts are frequent in many parts of the country in which crop production suffers the most. The intra-seasonal variations in rainfall distribution during crop growing periods, without a change in total seasonal amount, can also cause substantial reductions in yields of cereals, including maize. This means that the number of rainy days during the growing period is as important, as that of the total seasonal rainfall overall, rainfall variability costs Ethiopia over a - third of its growth potential and is likely to reduce it by $38 \%$, and to increase poverty by $25 \%$ over a 12 year period (Bank, 2010).

On top of this, no research was conducted to analyze climate change and variability of the study areas. Hence, the present study intends to analyze the alteration in temperature, precipitation and then number of rainy days. The study sites are Fitche, Gerbeguracha, Werejarso and Filiklik areas of North Shewa zone of Oromia. These sites were chosen because they are located in different altitude and agro-ecology.

\subsection{Problem of the Statement}

Climate change is emerging as one of the main challenges humankind will have to face for many years to come. It could become a major risk to world food security, as it has a strong effect on food production, access and distribution. Global atmospheric concentrations of anthropogenic greenhouse gases (Methane, Carbon dioxide and nitrous oxide) have increased markedly since 1950 . Due to this increase, global surface temperature has also been observed to have been increasing (IPCC, 2007). With accumulating evidence that greenhouse gas concentrations are warming the world's climate, research has increasingly focused on estimating the impacts that are likely to occur under different warming scenarios as well as how societies might adapt to a change in climatic conditions. Potential impacts of climate change on world food supply have been estimated in several studies (Parry., 2004). Results show that some regions may improve production, while others suffer yield losses. This could guide to shifts of agricultural production zones around the world.

Ethiopia Agriculture is intimately tied to the prevailing weather conditions. Thus, climate risk has historically been a major cause of food insecurity and famines. However, the relationships between climate variability and fluctuations in agricultural production at regional and sub-regional scales have not been studied in detail (Woldeamlak, 2009). Though little is known so far, about the impact of climate change on agriculture, water resource, construction and other sectors is due to result of increasing in temperature, reduced water availability and increased in atmospheric evapotranspiration and the changing rainfall levels. The study areas economy mainly depends on agricultural activities this agriculture also depends on seasonal and annual rainfall amount and distribution. So, there is no significant research conducted yet on the impact of climate change over the study areas in general.

\subsection{General Objective}

- To characterize the monthly, seasonal and annual climate variability and over the study areas.

- To assess number of rainy days over the study area for the periods of 1982 to 2014 .

\section{Materials and Methods}

\subsection{Physical Characteristics and Absolute Location}

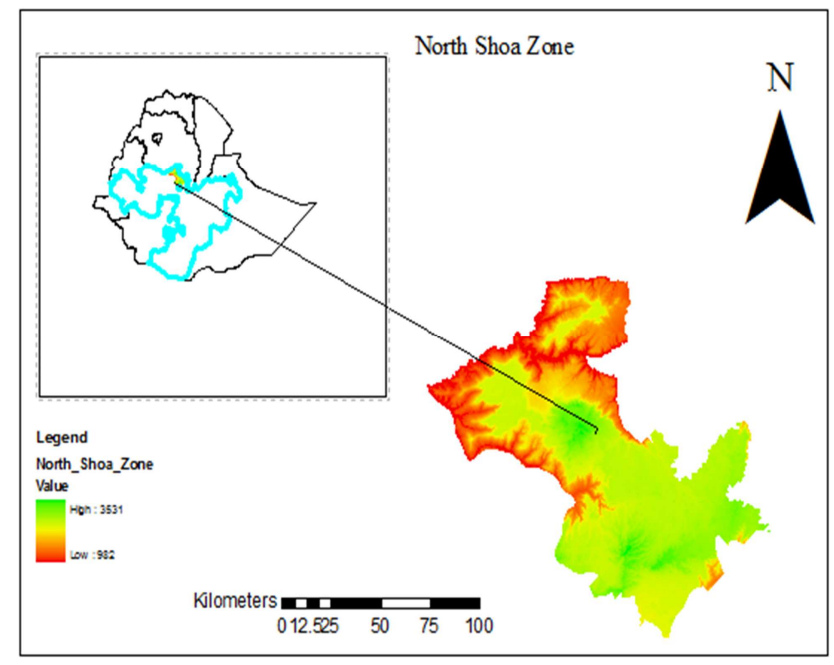

Figure 1. Description of the study area.

Oromia is the largest National Regional Government in the Federal Democratic Republic of Ethiopia and lies between $30040^{\prime}$ and $10035^{\prime}$ North latitude $34005^{\prime}$ to 43011' East longitude and covers a geographic area of about 364,606 square kilometers. Relatively Oromia is bordered by all national regional governments of Federal Republic of Ethiopia except Tigray national regional government. North Shewa zone comprises fourteen (14) districts, including Fiche Urban Administration and Fiche town is the administrative center of the zone which is $115 \mathrm{~km}$ North of Finfinne/Addis 
Ababa. Accordingly North Shewa zone is approximately located between $9008^{\prime} 52^{\prime \prime}$ to $10035^{\prime} 17^{\prime \prime}$ North latitude and 37056 '13" to 39034'47" East longitudes.

Based on the 2007 census conducted by the central statistical Agency of Ethiopia, North Shewa zone has a total population of both Urban and Rural are 728846, of whom 370648 are men and 358198 women (CSA, 2007).

\subsubsection{Topography}

North Shewa zone is characterized by dissected high plateaus and mountains associated with hills, valleys and gorges. Its altitude extends from about 1000located in Abay gorge in Wara Jarso district to over 3500 m.a.s.l. located in Degem district. The larger portion of the zone lies between altitudes ranging from 2500 to $3000 \mathrm{masl}$, followed by 1500 to 2000masl. Cheleleka (3571m), Gara Guda (3544m), Intoto (3211), and Elen are some of the major mountains found in the zone. In general, the study region is characterized with varied topographic features that resulted for the existence of micro climatic variation and endowment of different natural vegetation resources that contributes for good agricultural development.

\subsubsection{Soil types}

The major soils of North Shewa zone are Vertisols, Cambisols, Histosols, and Lithosols. Some other types of soils are also found here and there throughout the zone in association with other soils. Larger portions of the zone, that is central, eastern and eastern central portions of the zone largely lie under Vertisols, Lithosols and Cambisols. Similarly, Aerosols, Luvisols, Nitosols and rocks cover larger portions of the zone here and there. In general, most of the soils are found in association throughout the zone.

\subsubsection{Agro-ecology of the Study Area}

The traditional ecology of North Shewa zone ranges from upper Gammoojjii to Baddaa. About 23\% of the total area of the district is characterized by tropical / Gammoojjii climatic condition, while about 35 and $42 \%$ of the total area of the Zone are characterized by subtropical/Badda Daree and Baddaa agro-climatic/traditional ecological conditions respectively. North Shewa zone is characterized by two rainy seasons, namely summer and spring (locally known as Ganna and Arfaasaa rains respectively. Summer season lasts for about five months (June to October), while spring season similarly lasts for three months (March to May). Most of the areas of the zone experience mean annual rainfall ranging approximately between $800 \mathrm{~mm}$ and $1600 \mathrm{~mm}$.

Similarly, North Shewa zone experiences mean annual temperature ranging between 10 and $25^{\circ} \mathrm{C}$. According to the above mentioned project output, about $44.2 \%$ of the total area of the zone experiences average annual temperature ranging between 10 and $150 \mathrm{C}$. In the same fashion, about 38.3 and $17.5 \%$ of the total area of the zone experience mean annual temperature ranging from 15.1 to $20^{\circ} \mathrm{C}$, and 20.1 to $25^{\circ} \mathrm{C}$ respectively.

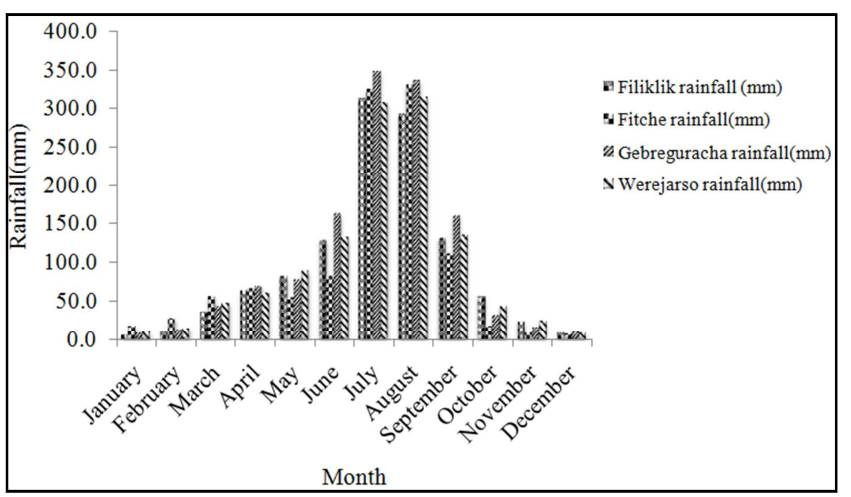

Figure 2. Monthly rainfall pattern of North Shewa (R4) Oromia region.

The climate pattern of North Shewa (R4) is characterized as bimodal type the highest peak of rainfall occurs during March to April and a major rainfall occur in July and August months. During Kiremt seasons the rainfall reaches $313 \mathrm{~mm}, 307 \mathrm{~mm}$, $348 \mathrm{~mm}$ and $324 \mathrm{~mm}$ in July and $293 \mathrm{~mm}, 314 \mathrm{~mm}, 336 \mathrm{~mm}$ and $330 \mathrm{~mm}$ in August at Filiklik, Werejarso, Gerbeguracha and Fitche respectively (Figure 2). Gerbeguracha has better monthly rainfall pattern than Filiklik, Werejarso and Fitche areas. Maximum temperature for the study areas is high during March to May months. The monthly maximum temperature is higher over Filiklik and Werejarso than Gerbeguracha and Fitche (3). While the average minimum temperature of Gerbeguracha and Fitche is the lowest than Filiklik and Werejarso.

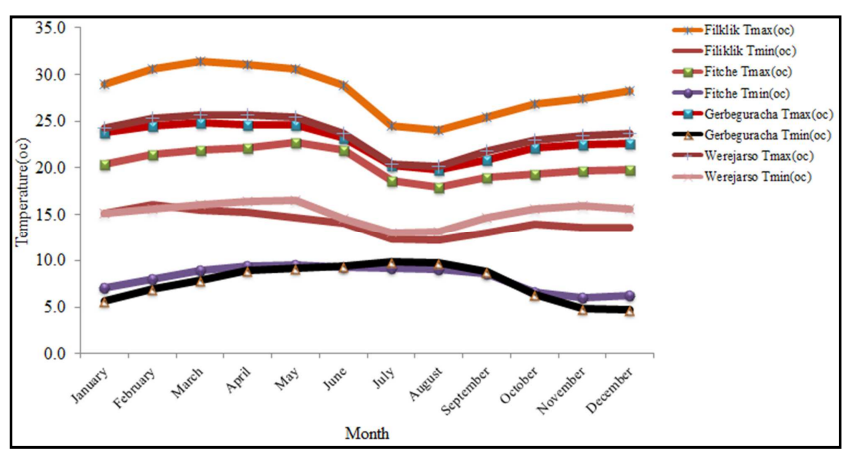

Figure 3. Maximum and Minimum temperature pattern of North Shewa (R4) Oromia region.

\subsection{Data and Methodology}

The historical daily climate data such as maximum, minimum temperature and rainfall observed data's were collected from the National Meteorological Agency (NMA) of Ethiopia. To conduct this research 4 stations having records from early 1982 to 2014 years and used for analyses. The station rain gauge network is not evenly distributed over the study area. The monthly total rainfall data quality was checked using Tamet, Excel sheet 2010 and INSTAT+ v. 3.37.

After re-arranging the data, the daily time series from each station and for each year were plotted and a visual examination was made to identify any obvious outliers. Suspected outlier data were checked for typographical error, and then cross-checked if neighbouring stations had such high 
rainfall. In such a process, no major anomalies were found. Monthly and annual time series were plotted and their values again checked for outliers.

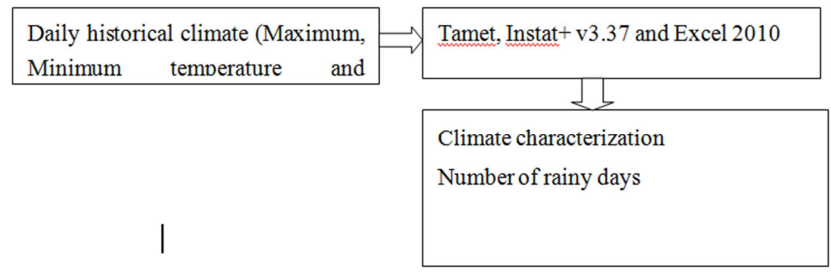

Figure 4. Workflow of the study.

\section{Result and Discussions}

\subsection{Rainfall Pattern of the Study Areas}

The mean annual and seasonal baseline rainfall for the last 32 years (1982-2014) in Filiklik, Werejarso, Gerbeguracha and Fitche is shown in Figure 5. The annual mean rainfall was $1060.0 \mathrm{~mm}, 1164.0 \mathrm{~mm}, 1228.0 \mathrm{~mm}$ and $1093 \mathrm{~mm}$ for Filiklik, Werejarso, Gerbeguracha and Fitche respectively. Though all of the study areas are located in vicinity, variable rainfall was observed as supported by Hadgu et al. (2013), who conducted research in different parts of Tigray region and found that high inter-annual variability of coefficient of variation of rainfall in Alamata, Adigudum, Mekelle, Edagahamus and Adigrat towns.
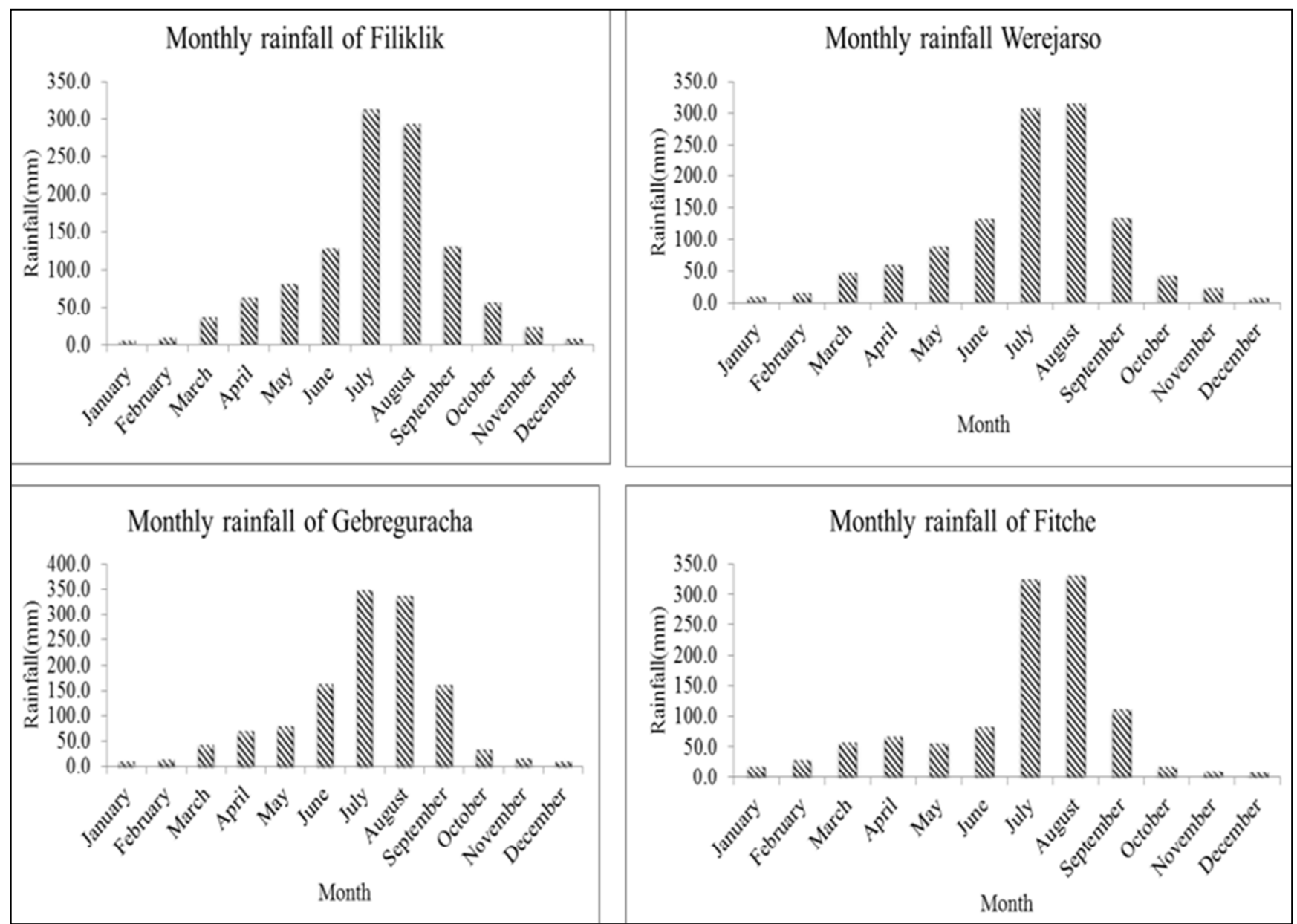

Figure 5. Monthly rainfall of North Shewa zone (R4) Oromia.

Figure 6 shows that the Kiremt (JJAS) seasonal rainfall contributed to most of the annual rainfall amount. Comparatively, Gerbeguracha had better rainfall amount than Filiklik, Werejarso and Fitche. Of the four months, the highest amount was recorded in July at all of the four places with mean monthly amount of $313 \mathrm{~mm}, 307 \mathrm{~mm}, 348 \mathrm{~mm}$ and $324 \mathrm{~mm}$ at Filiklik, Werejarso, Gerbeguracha and Fitche respectively during the last 32 years. The Belg (FMAM) rainfall amount is better during the month of April for all the study areas. The seasonal rainfall amount reaches up to $194 \mathrm{~mm}, 215 \mathrm{~mm}$,
$206 \mathrm{~mm}$ and $207 \mathrm{~mm}$ over Filiklik, Werejarso, Gerbeguracha and Fitche respectively.

The annual rainfall performance of the study areas for the last thirty two years was highly variable from year to year. The rainfall amount varies between $350-1677 \mathrm{~mm}, 439-1530 \mathrm{~mm}$, $282-1754 \mathrm{~mm}$ and $416-1540 \mathrm{~mm}$ over Filiklik, Werejarso, Gerbeguracha and Fitche respectively. While the annual mean rainfall was $1060 \mathrm{~mm}, 1164 \mathrm{~mm}, 1228 \mathrm{~mm}$ and $1100 \mathrm{~mm}$ for Filiklik, Werejarso, Gerbeguracha and Fitche respectively. The rainfall amount was better at Gerbeguracha than the other study 
sites for the periods of 1982-2014.

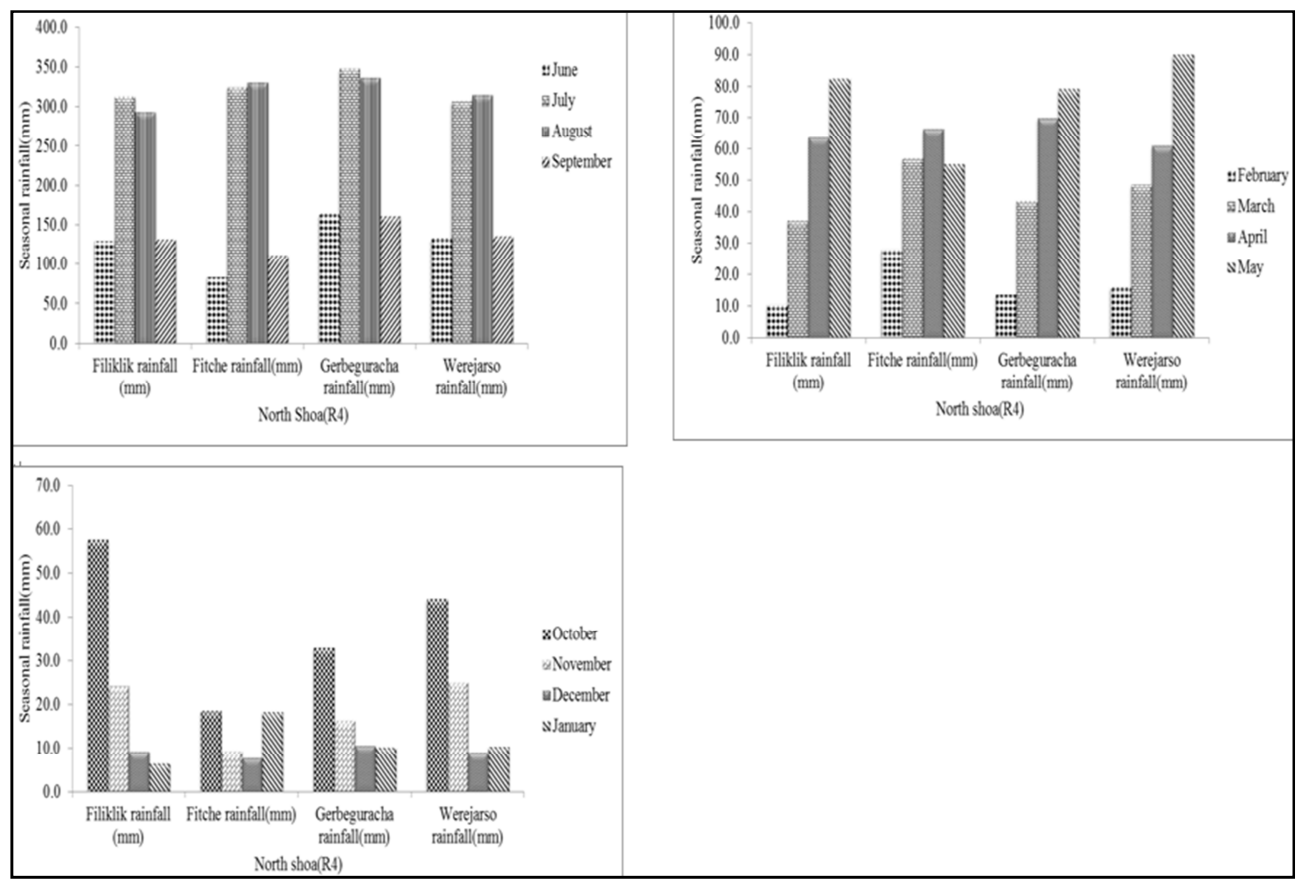

Figure 6. Seasonal rainfall performance of North Shewa (R4) zone of Oromia.

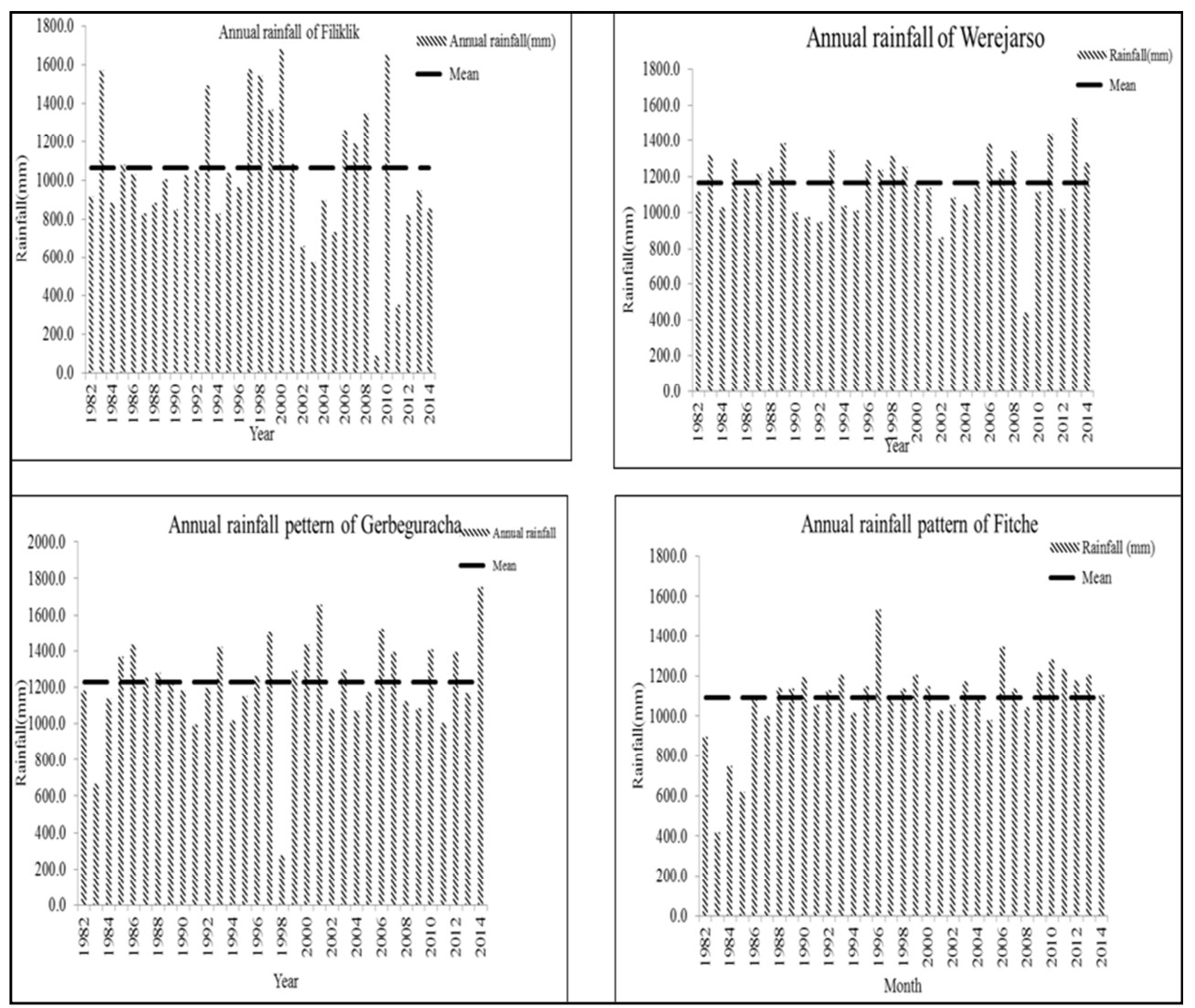

Figure 7. Annual rainfall pattern of North Shewa Zone (R4) Oromia.

The time series analysis of annual and seasonal mean rainfall is shown in Figure 8. The rainfall anomaly over Filiklik, Werejarso, Gerbeguracha and Fitche shows that highly variable from year to year for the last periods. The annual rainfall trend shows that both positive and negative anomalies for the last 32 years (1982-2014). The upward bar shows positive anomalies indicating that the rainfall was above the mean value and these years were wetter years while 
the downward bar shows negative anomalies indicating the rainfall was below normal from mean rainfall over Filiklik,

Werejarso, Gerbeguracha and Fitche (Figure 8).

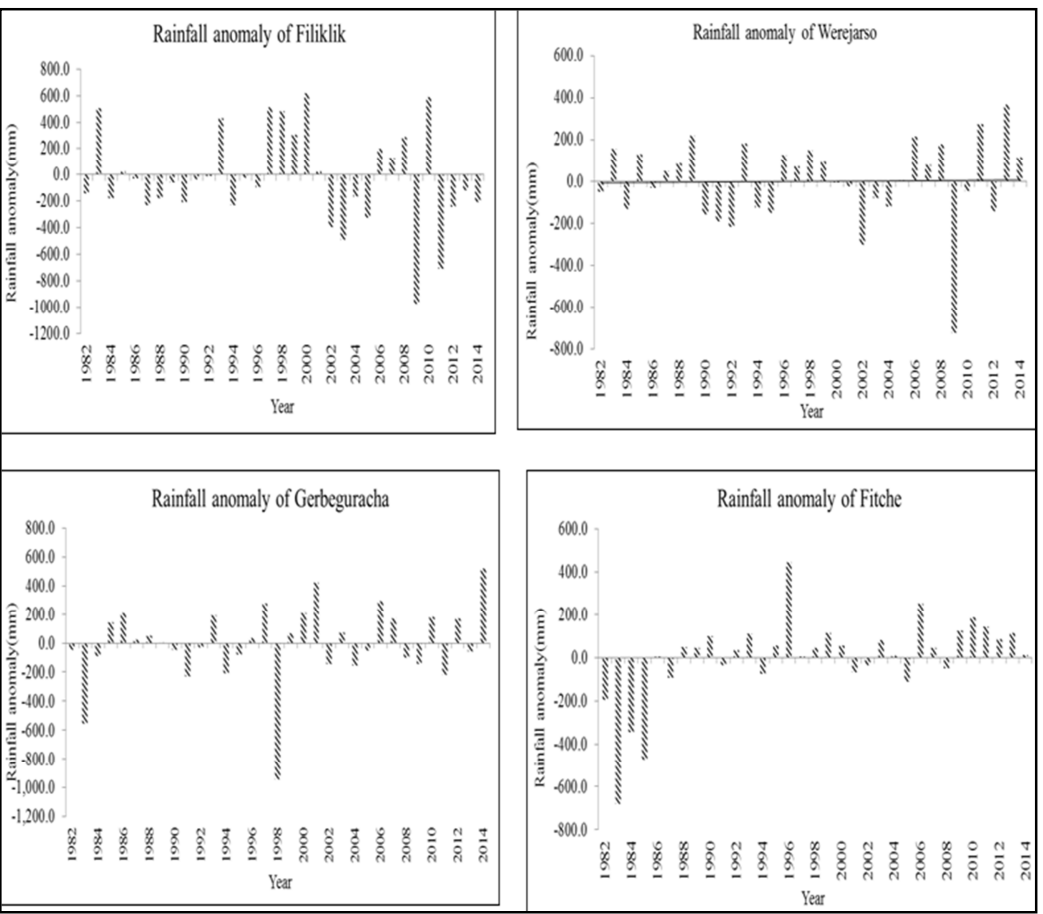

Figure 8. Rainfall anomaly of North Shewa zone (R4) Oromia.

\subsection{Temperature Pattern of the Study Areas}

The annual average maximum temperature of Filiklik, Werejarso, Gerbeguracha and Fitche varies between $9{ }^{\circ} \mathrm{C}$ and $30^{\circ} \mathrm{C}$. The maximum temperature varies between $21-32^{\circ} \mathrm{C}$, $22-25^{\circ} \mathrm{C}, 21-29^{\circ} \mathrm{C}$ and $19-22^{\circ} \mathrm{C}$ for Filiklik, Werejarso, Gerbeguracha and Fitche respectively with annual average temperature of $28^{\circ} \mathrm{C}, 23^{\circ} \mathrm{C}, 23^{\circ} \mathrm{C}$ and $20^{\circ} \mathrm{C}$. whereas the annual maximum temperature condition of Fitche was slightly less than the three study areas. On the other hand the annual average minimum temperature of the study areas varies between $4-17^{\circ} \mathrm{C}$. The minimum temperature of each site is $7-17^{\circ} \mathrm{C}, 11-17^{\circ} \mathrm{C}, 4-13^{\circ} \mathrm{C}$ and $6-9^{\circ} \mathrm{C}$ for Filiklik, Werejarso, Gerbeguracha and Fitche respectively with annual average of $14^{\circ} \mathrm{C}, 15^{\circ} \mathrm{C}, 7^{\circ} \mathrm{C}$ and $8^{\circ} \mathrm{C}$. The minimum temperature was slightly less in Gerbeguracha and Fitche than Werejarso and Filiklik areas.

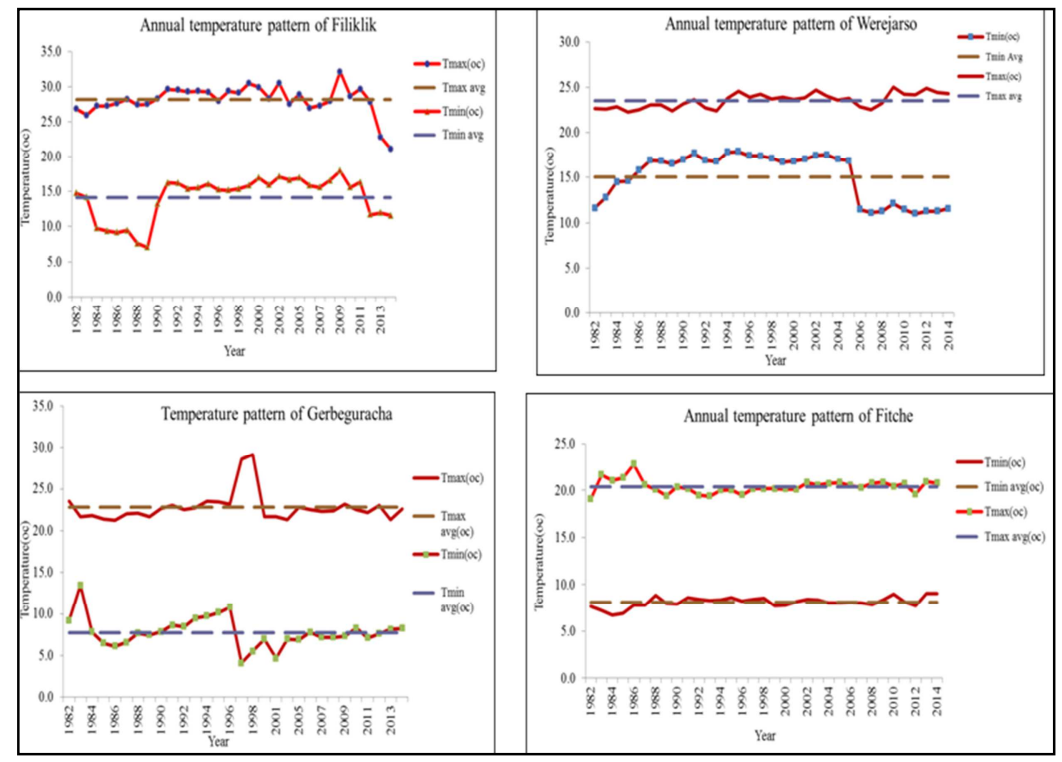

Figure 9. Annual temperature of North Shewa zone (R4) Oromia.

The maximum temperature trend line anomaly shows that in the few recent years' temperature increased on average by 0.5 to 
$1.5^{\circ} \mathrm{c}$ for the last 32 years over Filiklik, Werejarso, Gerbeguracha and Fitche (Figure 10). But the increment of maximum temperature over Werejarso and Filiklik was slightly higher than Gerbeguracha and Fitche.

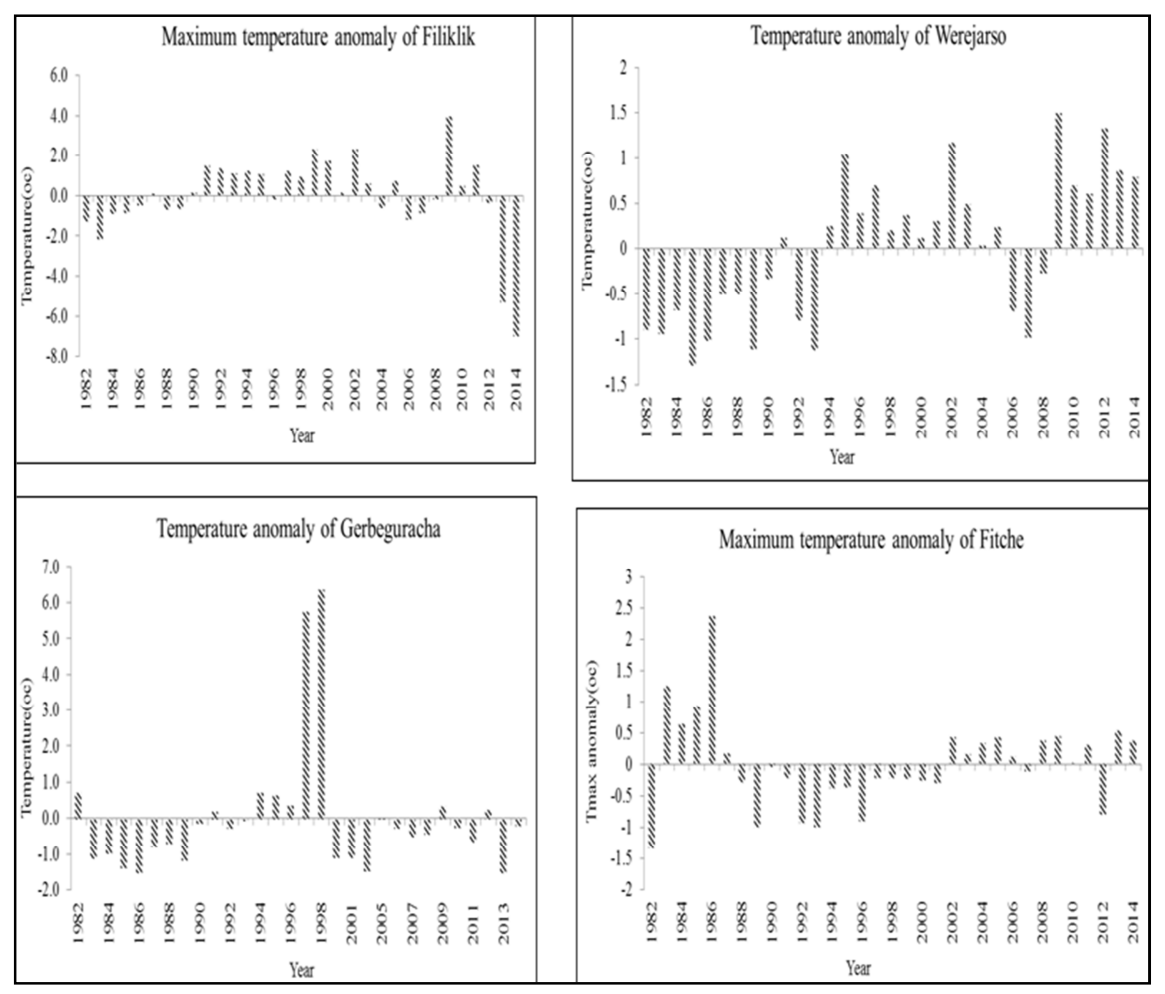

Figure 10. Maximum temperature anomaly of North Shewa zone (R4) Oromia.

The historical observed data of the last 32 years of minimum temperature anomaly shows that as the minimum temperature trend line shows slight variability from year to year over Filiklik, Werejarso, Gerbeguracha and Fitche (Figure 11). The minimum temperature increased by 0.5 to $2^{\circ} \mathrm{C}, 0.5$ to $1.5^{\circ} \mathrm{C}$ and 0.5 to $1.5^{\circ} \mathrm{C}$ over Filiklik, Gerbeguracha and Fitche respectively. On the other hand over the past recent years the minimum temperature radically decreased at Werejarso starting from 2006 to 2014.

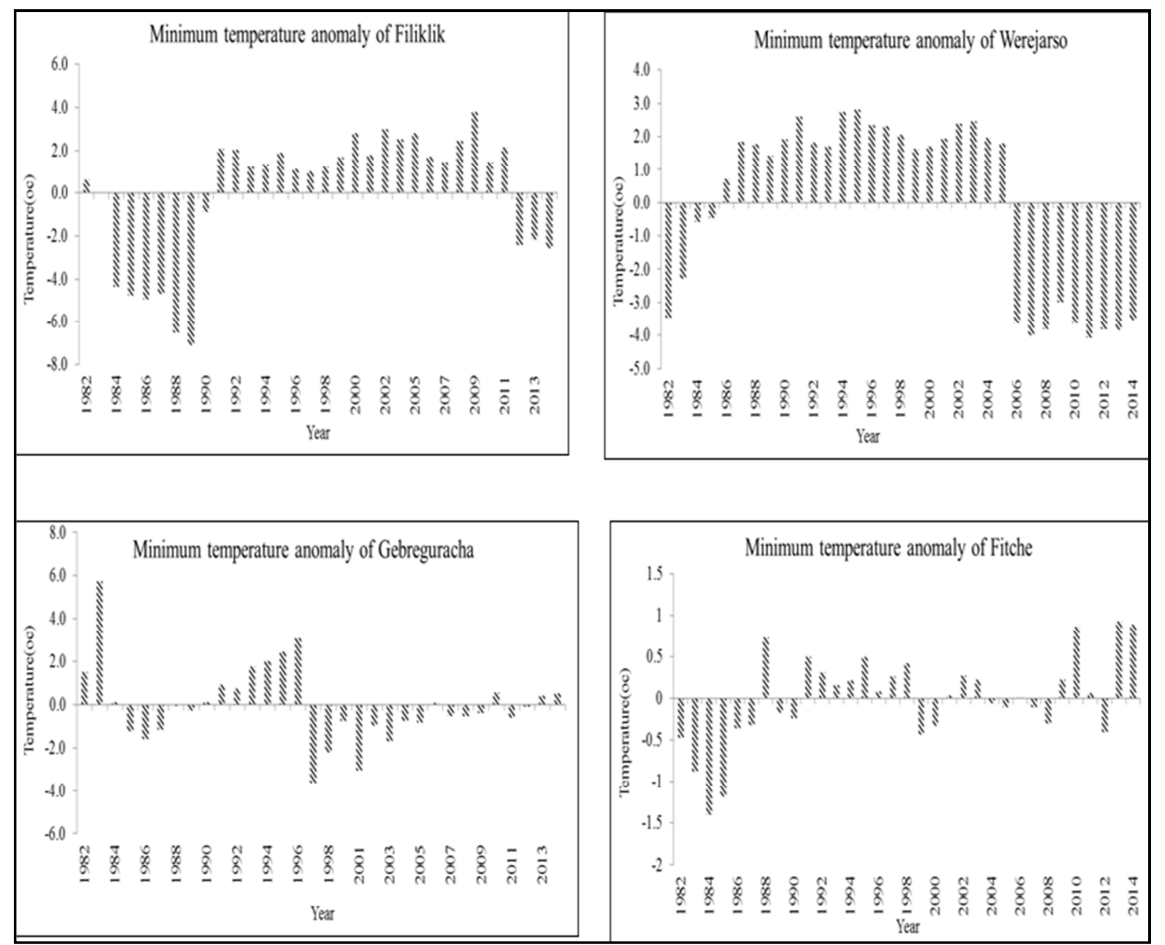

Figure 11. Minimum temperature anomaly of North Shewa zone (R4) Oromia. 


\subsection{Trends of Number of Rainy Days}

Daily rainfall analysis has revealed that the annual and June-September mean rainy days at 2 of the stations stationary and at 2 of station not stationary, where there is a significant decrease at the $5.8 \%$ and $4.2 \%$ over Filiklik and Werejarso respectively for the periods of 1982 to 2014 . The number of rainy days over the two study areas of Gerbeguracha and Fitche shows that an increment by $6.9 \%$ and $8.9 \%$ for the last periods.

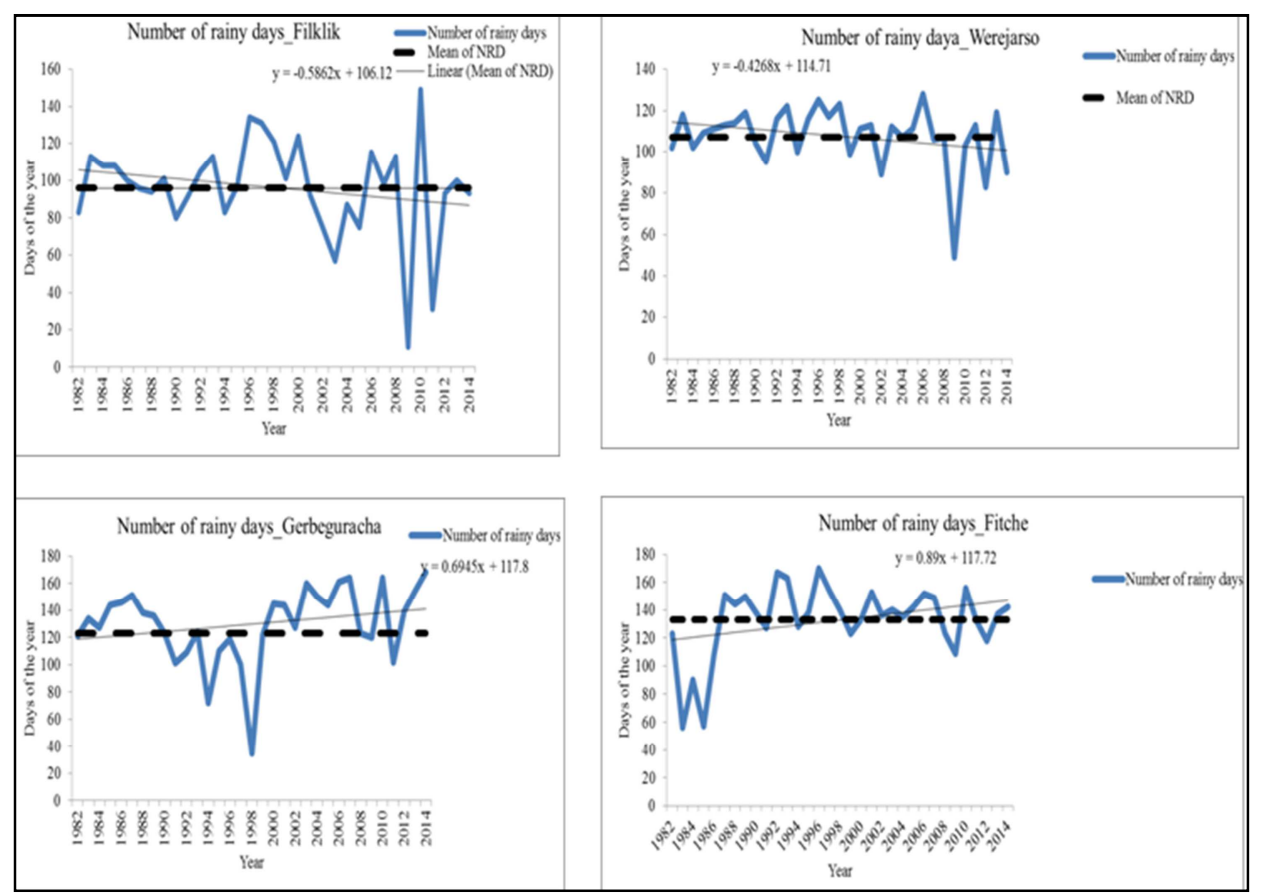

Figure 12. Number of rainy days of North Shewa (R4) zone of Oromia.

\section{Conclusion and Recommendations}

The analyzed historical long term climate data shows that there was variability in rainfall, temperature and number of rainy days from year to year for the four study areas (Filiklik, Werejarso, Gerbeguracha and Fitche). The analyzed maximum temperature anomaly showed that the maximum temperature over the study areas highly variable year to year. The increment of maximum temperature over Filiklik, Werejarso, Gerbeguracha and Fitche increased by 0.5 to $-2^{\circ} \mathrm{C}$, 0.5 to $1.55^{\circ} \mathrm{C}$ and 0.5 to $1.5^{\circ} \mathrm{C}$ and 0.5 to $1.5^{\circ} \mathrm{C}$ respectively for the last periods. While The rainfall amount varies between $350-1677 \mathrm{~mm}, 439-1530 \mathrm{~mm}, 282-1754 \mathrm{~mm}$ and $416-1540 \mathrm{~mm}$ over Filiklik, Werejarso, Gerbeguracha and Fitche respectively. The number of rainy days shows that decrement by $5.8 \%$ and $4.2 \%$ over Filiklik and Werejarso. On the hand numbers of rainy days were stationary over Gerbeguracha and Fitche for the last thirty two years.

- Strengthen of further research on the impact of climate change and variability on different socio-economic activities of the societies is very crucial.

- Awareness creation on the variability of climatological elements also significantly mandatory.

Acronyms

CSA: Central statistics Agency

$\mathrm{CO}$ : $\quad$ Carbon dioxide
GHG:

IPCC:

m a.s.l:

NMA:

R4:

UNDP:
Greenhouse gas

Intergovernmental panel on climate change Meter above sea level

National Meteorological Agency of Ethiopia Region four (Oromia)

United nation development program

\section{References}

[1] Alex, E. (2012). Resources, risk and resilience: Scarcity and climate change in Ethiopia, New York University Press.

[2] Anju, S. (2007). Assessing, predicting and managing current and future climate variability and extreme events, and implications for sustainable development. Background paper, UNFCCC workshop on climate related risks and extreme events under the Nairobi work programme on impacts, vulnerability and adaptation, 18-20 June 2007 - Cairo, Egypt. A paper commissioned by the secretariat of the United Nations Framework Convention on Climate Change.

[3] Bank, W. (2010). Economics of Adaptation to Climate Change: Effects of drought tolerance on maize yield in Sub-Saharan Africa, Research Report. World Bank, New York, USA.

[4] Challinor A. J., W., T. R., Craufurd, P. Q., Slingo, J. M. and Grimes, D. I. F (2004). Design and optimization of a large-area process-based model for annual crops. Elsevier. B. V. Agricultural and Forestry Meteorology 124 (2004) 99120.http://www.elsevier.com/locate/agrformet. 
[5] CSA (2007). Federal Democratic Republic of Ethiopia Population and Housing Census.

[6] Hadgu, G., Tesfaye, K., Mamo, G., and Kassa, B. (2013). Trend and variability of rainfall in Tigray, Northern Ethiopia: Analysis of meteorological data and farmers' perception. Envitomental sceinces.

[7] Hulme, M., Doherty, R. M., Ngara, T., New, M. G. and Lister, D. (2001). African climate change: 1900-2100. Climate Research 17(2): 145-168.

[8] IPCC (2001). Climate Change 2001. Impacts, Adaptation and Vulnerability. Contribution of Working Group II to the Third Assessment Report of theIntergovernmental Panel on Climate Change. Cambridge University Press, Cambridge, UK.

[9] IPCC (2007). Climate change Impacts, Adaptation and Vulnerability. Cambridge University Press, UK. pp. 127-131.
[10] McSweeney., C., New., M., Lizcano.,G. and Lu., X. (2010). The UNDP Climate Change Country Profiles Improving the Accessibility of Observed and Projected Climate Information for Studies of Climate Change in Developing Countries. Bulletin of the American Meteorological Society, 91, 157-166.

[11] Parry. (2004). Climate Change Impact Assessment on Crop Production in Albania. World Bank Study on Reducing Vulnerability to Climate Change in Europe and Central Asia (ECA) Agricultural Systems.

[12] Woldeamlak, B. (2009). Rainfall variability and crop production in Ethiopia Case study in the Amhara region In: Proceedings of the 16th International Conference of Ethiopian Studies, Trondheim. 